Review paper

\title{
The status of medical physics in radiotherapy in China
}

\author{
Hui Yan, Zhihui Hu, Peng Huang, Kuo Men, Ye Zhang, Lv-Hua Wang, Ye-Xiong Li, \\ Jian-Rong Dai *, Yi-Min Hu
}

Department of Radiation Oncology, National Cancer Center/National Clinical Research Center for Cancer/Cancer Hospital, Chinese Academy of Medical Sciences and Peking Union Medical College, Beijing 100021, China

\section{A R T I C L E I N F O}

\section{Keywords:}

Status

Medical physics

Radiation Oncology

China

\begin{abstract}
A B S T R A C T
Purpose: To present an overview of the status of medical physics in radiotherapy in China, including facilities and devices, occupation, education, research, etc.

Materials and methods: The information about medical physics in clinics was obtained from the 9-th nationwide survey conducted by the China Society for Radiation Oncology in 2019. The data of medical physics in education and research was collected from the publications of the official and professional organizations.

Results: By 2019, there were 1463 hospitals or institutes registered to practice radiotherapy and the number of accelerators per million population was 1.5. There were 4172 medical physicists working in clinics of radiation oncology. The ratio between the numbers of radiation oncologists and medical physicists is 3.51. Approximately, $95 \%$ of medical physicists have an undergraduate or graduate degrees in nuclear physics and biomedical engineering. $86 \%$ of medical physicists have certificates issued by the Chinese Society of Medical Physics. There has been a fast growth of publications by authors from mainland of China in the top international medical physics and radiotherapy journals since 2018.

Conclusions: Demand for medical physicists in radiotherapy increased quickly in the past decade. The distribution of radiotherapy facilities in China became more balanced. High quality continuing education and training programs for medical physicists are deficient in most areas. The role of medical physicists in the clinic has not been clearly defined and their contributions have not been fully recognized by the community.
\end{abstract}

\section{Introduction}

Medical Physics is the application of physics principles and methods to diagnose and treatment of human diseases [1]. The main roles of Medical Physicists in the clinical environment are to assess the qualities and performance of the imaging and cancer treatment equipment regularly [2]. In radiation oncology, they play crucial roles in designing radiation treatment plans with the consultation of oncologists and verifying radiation dose delivered to patients [3]. They work with physician, dosimetrists, therapists, nurses and engineers to provide high-quality patient care [4].

Diagnostic X-ray imaging was introduced to China shortly after the discovery of X-rays by Roentgen [5]. In the early years of 1930s, radiation treatment centers were established in Beijing, Guangzhou, and Shanghai at nearly the same time. The Sino-Belgian Radium Institute was the most prominent place which installed two $180 \mathrm{kV} \mathrm{X-ray} \mathrm{units}$ and $1 \mathrm{~g}$ of radium tubes [6]. Chinese medical physics was pioneered by
Prof. Xu Haichao in 1940s at Peking Union Medical College (PUMC). He worked with Prof. Marvin Williomus, an American medical physicist, to treat cancer patients using a $400 \mathrm{kV} \mathrm{X-ray} \mathrm{unit} \mathrm{[7].} \mathrm{The} \mathrm{department} \mathrm{of}$ radiology in Caner Institute of Chinese Academy of Medical Sciences (CICAMS) started to treat patients with a Cobalt-60 unit in 1958. At the same year, the division of radiation physics in CICAMS was founded. They made the manual multi-leaf collimator and installed it on Cobalt60 machine in 1965. Later, they made the remote control system for brachytherapy machine using Cobalt-60 source ball in 1965-1967 [8].

From 1970, China began to build linear accelerators and on-board imaging devices. As a result, $25 \mathrm{MeV}$ Betatron, Simulator and Cobalt60 brachytherapy machine were produced by Tianjing therapeutic instrument factory [9]. Meanwhile, Beijing Medical Apparatus and Instruments Institute built the first linear accelerator [10]. Since 1976, the major hospitals started to purchase high-end linear accelerators, CT, Brachytron and planning software from USA and Europe [11]. Following the clinical application of the linear accelerators, text books in Chinese

\footnotetext{
* Corresponding author.

E-mail address: dai_jianrong@cicams.ac.cn (J.-R. Dai).
} 
about the principle of radiation physics and treatment planning were published in 1979 [12]. In 1990s, 3D conformal radiotherapy started to be used and gradually became popular in the clinic [13]. In 2000, the first CT simulator, linear accelerator with multi-leaf collimator, and inverse treatment planning system were installed in CICAMS [14]. From then on, China stepped onto the stage of modern radiotherapy marked by intensity modulated of radiotherapy (IMRT) and image-guided radiotherapy (IGRT).

The Chinese Society of Medical Physics (CSMP) was founded in 1981 and registered as a branch of the Chinese Society of Biomedical Engineering (CSBME). In 1986, CSMP became national members of the AsiaOceania Federation of Organizations for Medical Physics (AFOMP), the International Federation for Medical and Biological Engineering (IFMBE), and the International Organization for Medical Physics (IOMP) [15]. CSMP started to publish its official journal in 1981 which later became the Chinese Journal of Medical Physics in 1993. The official website of CSMP was debuted in 2006, which published the most recent news and activities in medical physics [16]. CSMP hosted many international meetings and academic conferences every year. It cooperated with many international organizations including AAPM, EFOMP, IOMP, and IFMBE for joint tasks and meetings [17].

The education of the medical physicist in China can be traced back to 1979 when the department of engineering physics at Tsinghua University opened courses for graduates in nuclear medicine instruments. Later, CICAMS and PUMC offered courses for graduates in radiation physics. In 1994 Peking University established a medical physics division in the department of nuclear technology and application [18]. In 2003, the branch of medical physics and engineering was formed under the department of nuclear science and technology at Tsinghua University. Later, several famous universities established their medical physics programs in a school or department of nuclear science and engineering [19]. In 2011, the Ministry of Education and the State Council of China officially acknowledged medical physics as an independent discipline [20].

Since 1980, major cancer hospitals in China sent their medical physicists to Europe and USA for continuing education and academic exchange [21]. Many of them became directors of radiation physics division after their return to China. The new knowledge and experience they learned from foreign countries led them to realize the need to promote education and scientific programs for medical physicists in China. However, it suffered delays due to the shortage of funding and staff. Recently, this situation has changed with increasing financial investment in healthcare by the government [22]. Despite encouraging improvement in recent years, it should be noted that there is still a long way for them to catch up with the most advanced technologies in modern medical physics.

\section{Material and methods}

\subsection{Survey}

In 1986, The China Society for Radiation Oncology (CSTRO) launched the first nationwide survey on the status of staff and equipment in departments of radiation oncology [23]. Since then 9 surveys have been conducted, the most recent one was in 2019 (data collected during April - September) [24]. The questionnaire was sent to the chairs of CSTRO branches in 31 provinces, autonomous region, and provincelevel municipality. The chairs obtained the list of facilities qualified to perform radiotherapy in their regions, and sent the survey forms to the persons in charge of these facilities for more information. The questionnaires were collected and analyzed by the chairs of CSTRO branches and then sent back to the information office of CSTRO. All data were reviewed twice by staffs of branches and the information office of CSTRO.

The questionnaire was written in Chinese and covered the field of radiation oncology. The content relevant to medical physics was extracted from the questionnaire and listed as follows: (a) the number, title, certificate, foreign training experience, educational level, and age of medical physicists; (b) the involvement of medical physicists in the procedures of patient moulds and masks, CT scanning, CT simulation, patient positioning, plan reviewing and approval; (c) the status of continuing education and training of medical physicists; (d) the detail of the equipment and treatment planning systems for radiotherapy. In addition to the questionnaire, participants were encouraged to provide comments in any form. Certain information was also obtained by contacting chairs of CSTRO branches, CSMP President, training program directors, university faculties, etc.

\subsection{Publications}

The status of scientific research was mainly evaluated by the number of publications in a few top medical physics journals (Medical Physics, Physics in Medicine and Biology, and Physica Medica). These international journal are famous for their long history and high impact in this field. These publications were grouped in 9 subspecialties including radiation therapy, radiation imaging, magnetic resonance, ultrasound, biological physics, infrared and microwave, optical physics, tissue measurements, and radiation measurement. Within the subspecialty of radiation therapy, the publications were divided into 4 subfields including clinical implementation, plan optimization, plan evaluation, and quality assurance. Only those publications with all authors from the mainland of China were counted as ones contributed fully by Chinese authors. This selection rule might be strict but acknowledged as reasonable by most of institutes in China. All publications in the three journals between 2010 and 2020 was searched. The years before 2010 were excluded because the publications by Chinese author only in these journals are rare.

In addition to the international medical physics journals, the top radiation oncology journals including International Journal of Radiation Oncology•Biology•Physics (IJROBP), Radiotherapy and Oncology, and Radiation Oncology, were also selected. There are few publications about medical physics in these clinical radiation oncology journals but their influence is higher. There is a section reserved for physics contribution in IJROPB but not in the other two journals. Only those publications in medical physics with all authors from the mainland of China were counted. As these journals mainly focus on clinical practice, the expected publications by Chinese medical physicists only would be lower. The publications in the three international radiation oncology journals between 2010 and 2020 was searched.

\section{Results}

\subsection{Facilities and devices}

According to the 9-th survey conducted in 2019, a total of 1463 hospitals and institutes were registered to practice radiotherapy in China. Of these, $83 \%$ are public hospitals, $10 \%$ are private hospitals, and $6 \%$ are military hospitals. The number of hospitals and institutes registered to practice radiotherapy in China is shown in Fig. 1. The geographical distribution of the provinces, autonomous regions, and municipality and their ranking based on the number of radiotherapy facilities is shown in Fig. 2. The top five provinces with the most radiotherapy facilities are Shandong (100.4 M population), Henan ( $96 \mathrm{M}$ population), Jiangsu (80.5 M population), Hebei (75 M population), and Sichuan (83.4 M population). The two major metropolitans, Beijing (21.5 M population) and Shanghai (24.2 M population), ranked 13 and 15. The top five regions with the highest number of linear accelerators per million population are Beijing (3.73), Shanghai (2.54), Shandong (2.35), Henan (1.93), and Jiangsu (1.84).

The number of hospitals and institutes registered to practice radiotherapy as reported by the 9-th surveys are shown in Fig. 3 . There is a rapid increase in treatment facilities after 2001. This is due to the fast 


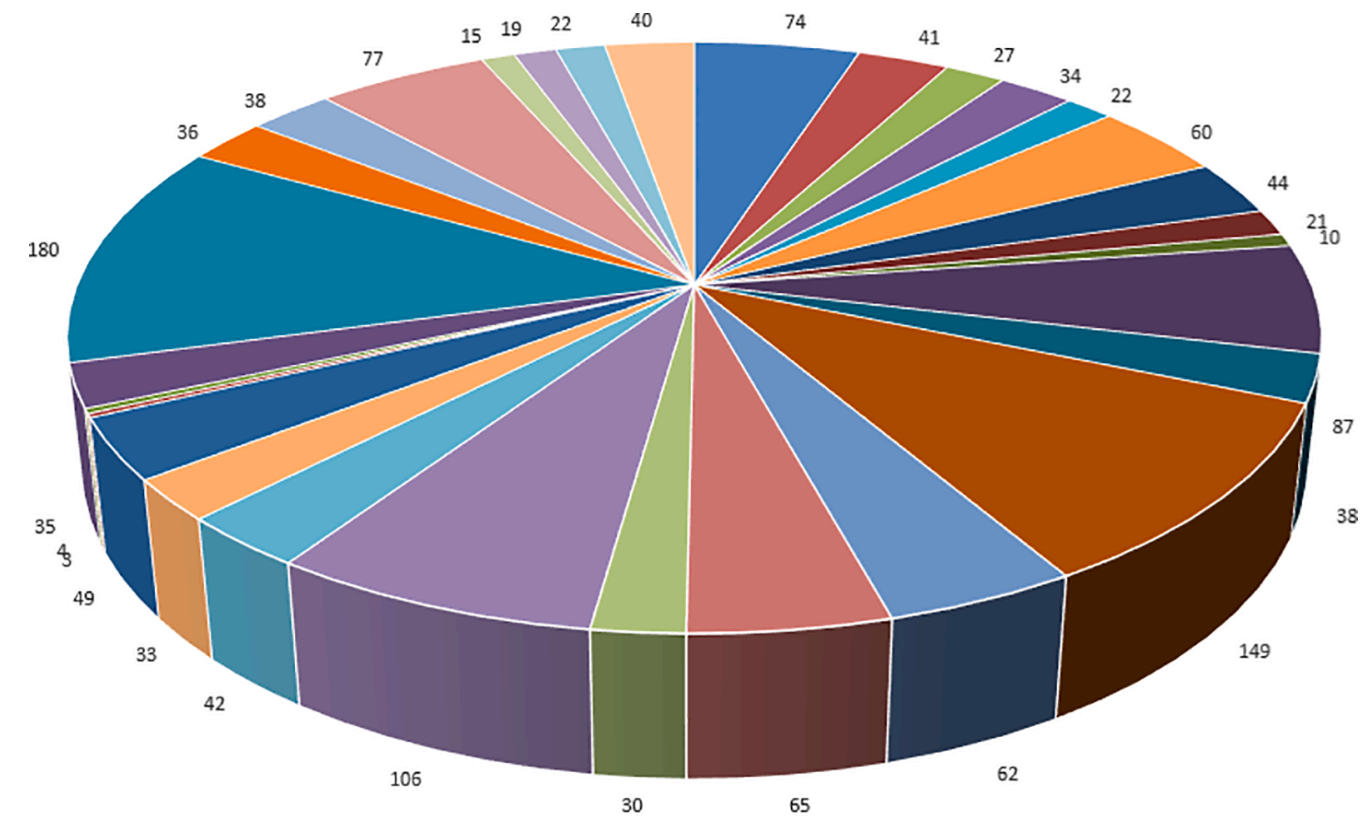

\begin{tabular}{|c|c|c|c|c|c|}
\hline - Anhui & a Beijing & घ Chongqing & • Fujian & - Gansu & ॥ Guangdong \\
\hline - Guangxi & - Guizhou & - Hainan & - Hebei & - Heilongjiang & - Henan \\
\hline a Hubei & Hunan & " Inner Mongoliz & घ Jiangsu & च Jiangxi & \# Jilin \\
\hline - Liaoning & a Ningxia & घ Qinghai & E Shaanxi & - Shandong & घ Shanghai \\
\hline Shanxi & "Sichuan & " Tianjin & "Xinjiang & " Yunnan & $\|$ Zhejiang \\
\hline
\end{tabular}

Fig. 1. The number of hospitals and institutes registered to practice radiotherapy in provinces, autonomous regions, and municipality in China.

growth of the Chinese economy and healthcare for cancer patients during this period. After 2015, the increase of treatment facilities was lower. It should be noted that although there is a rapid increase in the number of treatment facilities in most of regions, a few regions with poor economy are still far below the average. As shown in Figs. 1 and 2, there are 0,3 , and 4 radiotherapy facilities in Tibet (3.3 M population), Ningxia (6.8 M population), and Qinghai (6.0 M population).

The number of medical devices in the three major specialties (radiation therapy, diagnostic radiology, and nuclear medicine) as of 2019 was investigated. The top three devices with the highest number in radiation therapy are the linear accelerator (2021), radiotherapy simulator (1453), and CT simulator (355) as shown in Fig. 4a. Proton and ion facilities are very rare in China but their number has increased in recent years. The MRI-Linac is currently in clinical trial and waiting for approval by government [25]. The top three devices in diagnostic radiology are fluoroscopy/interventional radiology $(59,000)$, general radiography $(52,000)$, and CT scanner $(21,000)$ as shown in Fig. 4b. It should be noted that MRI is not only used for diagnosis, but also for treatment verification and planning in radiotherapy. The top three devices in nuclear medicine are SPECT/CT (390), SPECT (342), and PET/ CT (298) as shown in Fig. 4c. There are 8 PET/MRI units and 29 standalone Gamma Cameras in clinical service.

The change in the number of medical devices in radiation therapy are summarized in Table 1 . The number of linear accelerators keeps increasing annually and there was a rapid growth between 2011 and 2015. The number of cobalt 60 units increases until 2006 and is then gradually phased out from the departments of radiation oncology. The number of brachytherapy units increases until 2006 and then remains the same afterward. The number of X-ray simulators has not increased since 2015 but the number of CT simulators has decreased significantly since 2015. There are 100 photon and heavy ion facilities under planning and construction. Its number is envisaged to increase in the future.

\subsection{Occupation}

The number of staff in the departments of radiation oncology is summarized in Table 2. The number of medical physicists in radiation therapy is 4172 , while the number of medical physicists in diagnostic radiology and nuclear medicine are 150 and 105, respectively. The ratio between the number of radiation oncologists and medical physicists decreased from 9.53 in 1986 to 3.51 in 2019 . The number of medical physicists at age $30-35$ and $36-50$ is 2774 and 1249 , respectively. They represent $66.4 \%$ and $29.9 \%$ of the total number of medical physicists. The number of medical physicists with doctor, master, and bachelor degrees are 161,1184 , and 2654 , respectively. They represent $3.8 \%$, $28.3 \%$, and $63.6 \%$ of the total number of medical physicists. The number of medical physicists with post-doctoral experience or foreign degrees is 30. The number of medical physicists with short training experience at foreign countries, such as visiting scholar or academic exchange, is 264 . Together they represent $7.0 \%$ of the total number of medical physicists.

The number of medical physicists working in public, private, and military hospitals is 3602,288 , and 240 , respectively. The public healthcare systems accounts for $86.2 \%$ of the total positions while the others (private and military hospitals) accounts for $12.6 \%$. The number of medical physicists with certification issued by CSMP is 3590 which represents $86 \%$ of the total number. The percentages of medical physicists with junior, intermediate, and senior career titles are $48.1 \%$, $40.7 \%$, and $11.2 \%$, of the total number of medical physicists. The percentages of engineers with junior, intermediate, and senior career titles are $30.8 \%, 53.4 \%$, and $15.8 \%$, of the total number of engineers. Comparatively, the percentages of radiation oncologists with junior, intermediate, and senior career titles are $33.7 \%, 39.9 \%$, and $26.4 \%$, of the total number of radiation oncologists. The radiation oncologists with senior career titles are twice that of medical physicists.

In $2019,3.92$ million people $(0.28 \%$ of total population in China) 

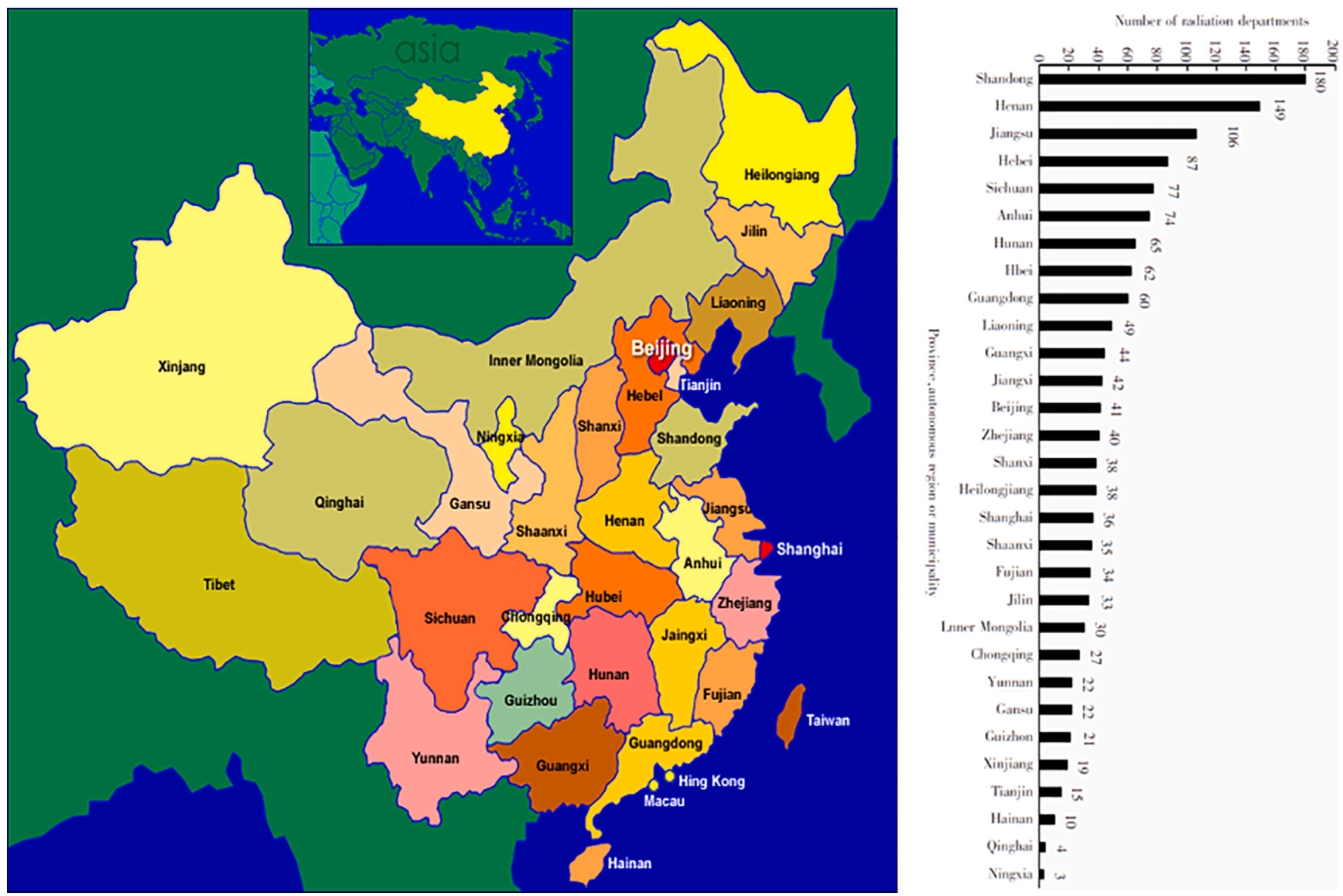

Fig. 2. The geographical distribution of the provinces, autonomous regions, and municipality in China and their ranking based on the number of radiotherapy facilities.

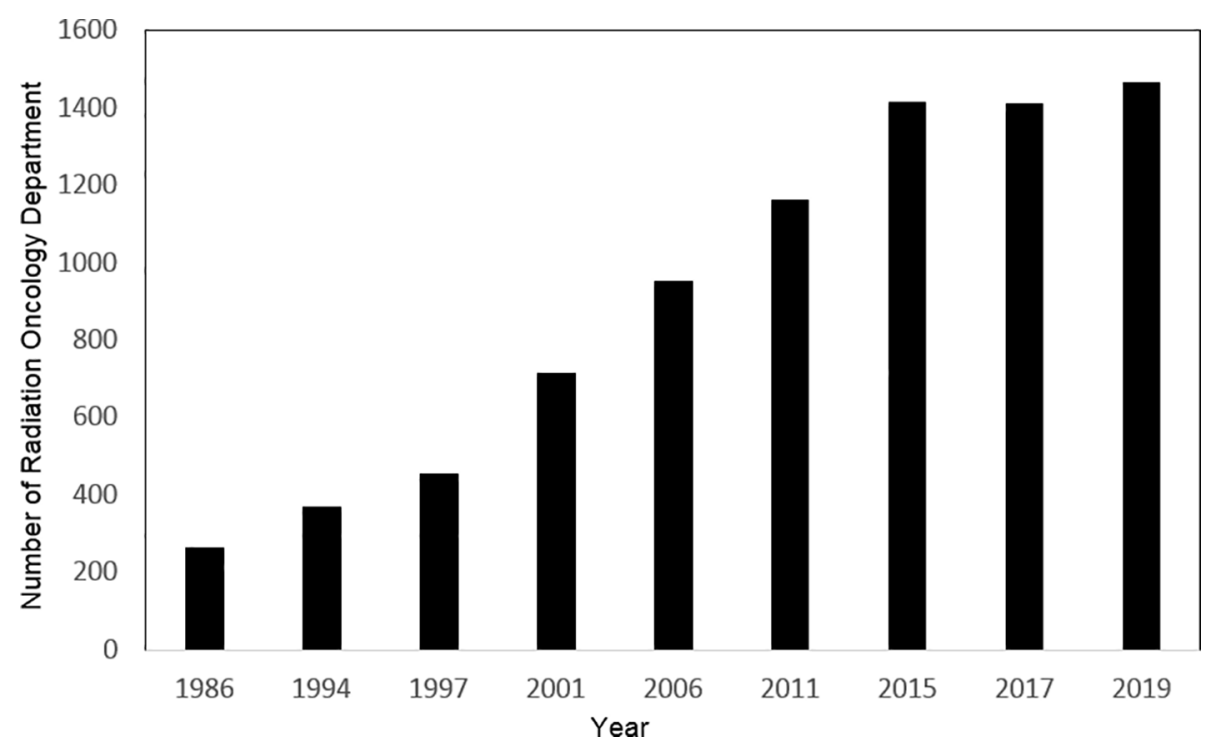

Fig. 3. The number of hospitals and institutes registered to practice radiotherapy in 9 national surveys (1986-2019) conducted by CSTRO.

were diagnosed with cancer and 1.26 million people treated with radiotherapy [26]. The number of patients per medical physicist is approximately 302 which is below the expected value of 400 for the developed countries in the Asia-Pacific region [27]. The number of Megavolt machines for radiotherapy per medical physicist is 0.58 , which is less than the expectation value 0.92 for the developed countries in the Asia-Pacific region [27]. The ratio of Megavolt machines per million population is only 1.5 , while the expected ratio is 6.7 for the developed countries, such as USA and Europe Countries $[28,29]$.

\section{Education}

Education of medical physics is provided at bachelor, master, and doctor degree levels. The requirement to enter a master program is a 


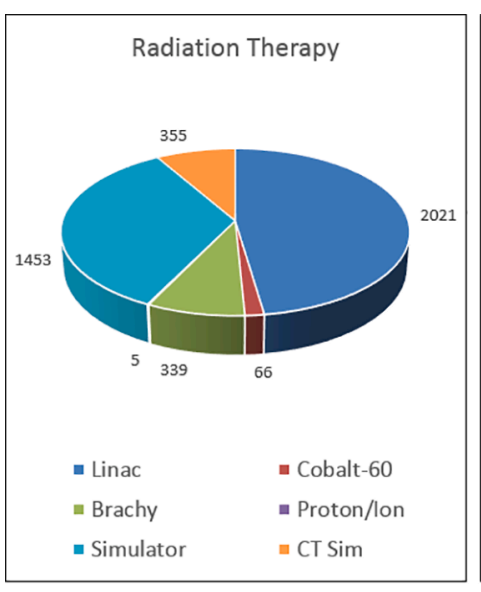

(a)

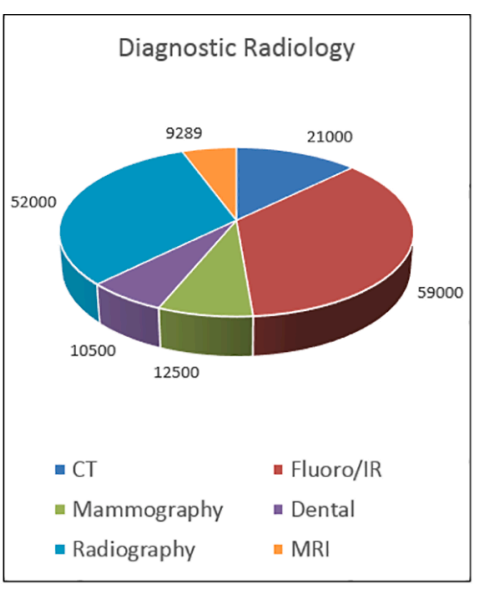

(b)

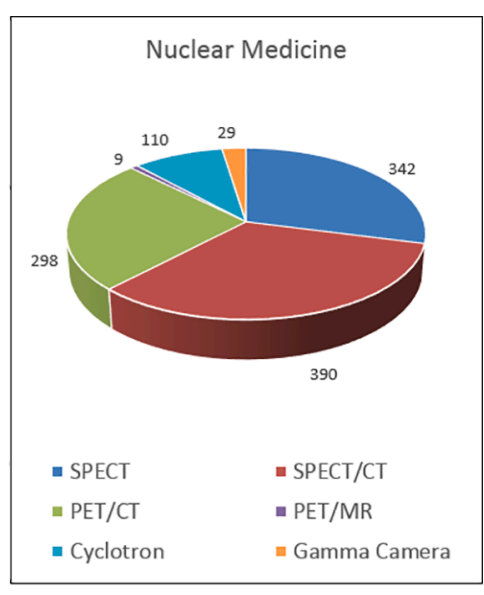

(c)

Fig. 4. The numbers of medical devices in the three major specialties of medical physics.

Table 1

The number of treatment units and imaging devices in departments of radiation oncology in 9 national surveys (1986-2019) conducted by CSTRO.

\begin{tabular}{llllllll}
\hline \multirow{2}{*}{ Year } & \multicolumn{2}{l}{ Treatment } & & & \multicolumn{2}{l}{ Simulation } \\
\cline { 2 - 3 } & Linac & Cobalt-60 & Brachy & Proton/Ion & & Simulator & CT Sim \\
\hline 1986 & 71 & 224 & 78 & - & 100 & - \\
1994 & 164 & 304 & 217 & - & 170 & - \\
1997 & 286 & 381 & 282 & - & 332 & - \\
2001 & 542 & 454 & 379 & - & 577 & - \\
2006 & 918 & 472 & 400 & - & 827 & 214 \\
2011 & 1296 & 286 & 317 & - & 376 & 1427 \\
2015 & 1931 & 93 & 439 & 2 & 1051 & 1353 \\
2017 & 1851 & 73 & 365 & 5 & 1622 & 825 \\
2019 & 2021 & 66 & 339 & 5 & 1453 & 355 \\
\hline
\end{tabular}

Table 2

Staff of departments of radiation oncology in 9 national surveys (1986-2019) conducted by CSTRO.

\begin{tabular}{llllll}
\hline Year & $\begin{array}{l}\text { Radiation } \\
\text { oncologist }\end{array}$ & $\begin{array}{l}\text { Medical } \\
\text { Physicist }\end{array}$ & Therapist & Engineer & Nurse \\
\hline 1986 & 1715 & 180 & 1410 & 312 & 1062 \\
1994 & 2764 & - & 2212 & - & 2361 \\
1997 & 3440 & 423 & 2245 & 730 & 3094 \\
2001 & 5113 & 619 & 3465 & 932 & 5002 \\
2006 & 5247 & 1181 & 4559 & 1141 & 6864 \\
2011 & 9895 & 1887 & 6103 & 1411 & 11,689 \\
2015 & 15,841 & 3294 & 8454 & 938 & 23,152 \\
2017 & 16,301 & 3709 & 8363 & 1405 & 19,939 \\
2019 & 14,575 & 4172 & 8940 & 1409 & - \\
\hline
\end{tabular}

bachelor degree in physics, radiology technology, nuclear engineering, radiotherapy technology and other relevant engineering fields. There are many universities and affiliated cancer hospitals that offer undergraduate and graduate education in medical physics. The selection process involves a nation-wide written exams but no interview is required. For doctor degree applicants, after the candidate passes the national exams there is an additional interview. These competitive entrance exams occur only once per year and are conducted by the Ministry of Education.

There are several undergraduate programs for the education of medical physicists in China, such as Shandong First Medical University (SFMU) [30], University of South China [31], and Mudanjiang Medical University [32], etc. Among them, SFMU (or Taishan Medical College) provides the largest undergraduate program. Their faculties consist of 16 professors, 20 associate professors, and 23 assistant professors and lecturers. The number of students enrolled annually is approximately 100. The core courses cover diagnostic medical imaging, medical imaging physics, radiation therapy physics, medical imaging and treatment device, radiobiology, Clinical Radiation Oncology, medical imaging process, etc. Most of their alumni are the therapists in the major cancer hospitals in China.

Graduate programs of medical physics are provided in many prestigious universities, such as Peking University and Tsinghua University. Table 3 lists the most famous programs which offer MS and $\mathrm{PhD}$ degrees in medical physics as of 2020. As one of the most successful program, the medical physics graduate program at Wuhan University celebrated its 15-th anniversary in 2018 [33]. Their alumni became the core force of medical physics in many top cancer hospitals. It should note that the largest number of graduate programs are to be found in North China followed by South China, East and Central China. So far, there are no medical physics graduate programs in West China.

There are a few resident training programs provided by top cancer hospitals for junior medical physicists, which are listed in Table 4. Every year, many young medical physicists are trained in these top hospitals for continuing education. During this period (half or one year), they are systematically trained by the experienced senior medical physicists and learn how to use a variety of treatment machines, treatment planning systems, and QA devices. It should note that these cancer hospitals usually have the best clinical devices and medical physics groups in China. Geographically, these hospitals are located in the cities of Beijing, Shanghai, Guangzhou, and Jinan. They represent the best cancer hospitals in North China, South-East China, South China, and East China.

\section{International participation}

As the official organization of Chinese medical physicists, CSMP has formed eight working groups in radiation physics, imaging physics, medical biophysics, biomedical signal, Hemorheology physics, education, nuclear medicine, radiation protection [16]. Annually, there is a CSMP meeting and a joint meeting (mainly covering region of Beijing, Tianjing, and Hebei) for all members. Local branches of CSMP hold an annual meeting for each province or metropolitan area. Biennially, there is the Great Wall international congress of medical physics and IEEE international conference on medical imaging physics and engineering. In 2012, CSMP successfully hosted the World Congress on Medical Physics and Biomedical Engineering in Beijing. With the joint effort of CSMP and NACMPA (the North American Chinese Medical Physicists Association), the 20-th International Conference on the Use of Computers in Radiation Therapy will be held in Beijing at 2022.

In the past two decades, the members of CSMP have been actively 
Table 3

Top universities providing medical physics graduate programs in China.

\begin{tabular}{|c|c|c|c|c|c|}
\hline Region & University & Major & Programs & Date of Establishment & Number of Graduates \\
\hline North & Peking Union Medical College & Radiation Physics & MS, $\mathrm{PhD}$ & 1993 & 5 \\
\hline North & Peking University & Imaging Physics & MS, PhD & 1994 & 5 \\
\hline North & Tsinghua University & Biomedical Engineering & MS & 2003 & 10 \\
\hline Central & Wuhan University & Medical Physics & MS & 2003 & 10 \\
\hline South & Sun Yat-sen University & Medical Physics & MS, PhD & 2005 & 3 \\
\hline South & University of South China & Nuclear Science and Technology & MS & 2007 & 5 \\
\hline East & University of Science and Technology of China & Nuclear Science and Technology & MS, PhD & 2012 & 5 \\
\hline North & Beihang University & Medical Physics & MS, PhD & 2018 & 10 \\
\hline
\end{tabular}

Table 4

Top hospitals providing medical physics resident training programs in China.

\begin{tabular}{|c|c|c|c|c|}
\hline City & Hospital & Major & $\begin{array}{l}\text { Period } \\
\text { (Year) }\end{array}$ & $\begin{array}{l}\text { Number Of } \\
\text { residents }\end{array}$ \\
\hline Beijing & $\begin{array}{l}\text { Cancer Hospital } \\
\text { Chinese Academy of } \\
\text { Medical Science }\end{array}$ & $\begin{array}{l}\text { Radiotherapy } \\
\text { Physics }\end{array}$ & $0.5-1$ & 30 \\
\hline Shanghai & $\begin{array}{l}\text { Fudan University } \\
\text { Cancer Center }\end{array}$ & $\begin{array}{l}\text { Radiotherapy } \\
\text { Physics }\end{array}$ & $0.5-1$ & 8 \\
\hline Guanzhou & $\begin{array}{l}\text { Sun Yat-sen } \\
\text { University Cancer } \\
\text { Center }\end{array}$ & $\begin{array}{l}\text { Radiotherapy } \\
\text { Physics }\end{array}$ & $0.5-1$ & 30 \\
\hline Jinan & $\begin{array}{l}\text { Shandong Cancer } \\
\text { Hospital }\end{array}$ & $\begin{array}{l}\text { Radiotherapy } \\
\text { Physics }\end{array}$ & $0.25-1$ & 60 \\
\hline
\end{tabular}

involved in several international professional organizations. Prof. Yimin $\mathrm{Hu}$, the vice director of Radiation Oncology department at CICAMS was elected as the national member of IOMP at 1986 and the president of AFOMP during 2012-2015 [34]. Prof. Shanglian Bao, the director of medical physics program at Peking University, was elected as the Chair of Science committee of AFOMP during 2004-2009 [35]. Prof. Yubo Fan, the dean of School of Biological Science and Medical Engineering at Beihang University, was the council member of World Council of Biomechanics (2002-2014) [36]. Prof. Jiahong Gao, the director of MRI center at Peking University, was elected as the president of the Organization for Human Brain Mapping (OHBM) in 2018 [37]. Xiance Jin, the vice director of Radiation and Medical Oncology Department at the First Affiliated Hospital of Wenzhou Medical University, was elected as the current Chair of Education and Training committee of AFOMP during 2019-2021 [38].

\section{Scientific research}

There has been a fast growth of funding by the Chinese government in recent years to meet the increasing demand for the development of industry and business. For medical physics research, the main research funding agencies are the national natural science foundation of china (NSFC) and the Ministry of science and technology of China (MSTC). NSFC funding covers several categories for various types of research projects including general program, key program, major Program, and joint program etc. For the ongoing projects, it can be accessed online by NSFC website [39]. NSFC mostly focuses on new developments in specific science and engineering specialties. MSTC also provides funding for cancer diagnosis and treatment research and focuses on developments and implementation of new technologies in healthcare. Its funding covers several categories for different research projects including national program on key research project, national key technologies $R \& D$ program, and national research priorities program etc [40]. In addition, there are the other funding resources provided by the Ministry of Education of China, the Chinese Academy of Sciences, governments of provinces and cities, and healthcare companies, etc. Compared with funding from the NSFC and MSTC, these funds are smaller and limited to certain fields. To extend the current funding resource the government encouraged researchers in medical physics to develop new techniques and projects on interdisciplinary and industrial subjects.

Over the past decade, great efforts have been made in healthcare research, especially in developing new devices and approaches for cancer treatment. Fig. 5 shows the number of publications in three top medical physics journals by authors from the mainland of China between 2010 and 2020. There was a rapid increase of publications in the subspecialties of radiation imaging and radiation therapy after 2017. The number of publications at 2018 is twice that in 2017 . The changes in the other 7 subspecialties are relatively smaller in recent years. The percentages of publications from all 9 subspecialties between 2010 and 2020 are shown in Fig. 6. The top three subspecialties are radiation imaging (218 papers), radiation therapy (70 papers), and magnetic resonance (42 papers). Within the subspecialty of radiation therapy, the number of publications are 15 papers in the field of clinical implementation [41-55], 11 papers in the field of plan optimization [56-66], 14 papers in the field of plan evaluation [67-80], and 12 papers in the field of quality assurance [81-92].

The publications contributed by Chinese medical physicists to the two top clinical journals (red and green journals) are rare but expected to increase in the future. There was only 1 paper [93] and 5 papers [94-98] found in IJROBP and Radiotherapy and Oncology, respectively, in past ten years. However, for the Journal of Radiation Oncology (RO), 62 publications were contributed by Chinese medical physicists. Between 2010 and 2015, the total number of publications in RO is 19 [99-117] and averagely 3 papers by Chinese authors were published per year. After 2015, the number of publications is increased significantly. There are 9 publications in 2016 [118-126], 7 publications in 2017 [127-133], 10 publications in 2018 [134-143], 9 publications in 2019 [144-152] and 8 publications in 2020 [153-160]. Within the subspecialty of radiation therapy, the numbers of publications in the fields of clinical implementation, plan optimization, plan evaluation and quality assurance are 23 papers (37\%), 16 papers (26\%), 14 papers (23\%) and 9 papers $(14 \%)$, respectively.

\section{Discussion}

The result of Figs. 1 and 2 show a clear imbalance in the geographical distribution of radiation devices and facilities. The top 10 provinces own $70 \%$ of radiotherapy facilities for $50 \%$ of the total population of China. Two major municipalities, Beijing and Shanghai, have the highest number of linear accelerators per million population. This number is even higher than those of developed counties. It indicates that the region with the higher population usually have a better economy, which in turn has the finance to support more radiotherapy facilities. However, for the other $50 \%$ of the population in $60 \%$ of the provinces, the percentage of radiotherapy facilities are relatively lower. This suggests that the government should pay more attention to the less developed regions and reduce excessive construction of radiotherapy facilities in the developed regions.

Although there is a fast growth of medical physicists in hospitals, it is clear that the number of medical physicists in China is still insufficient. As indicated by $\mathrm{Hu}$ [17], to meet the rapid increase of radiation treatment and diagnostic imaging devices in the 10 years from 2007, the number of new medical physicists required is $3000-5000$ in radiation 


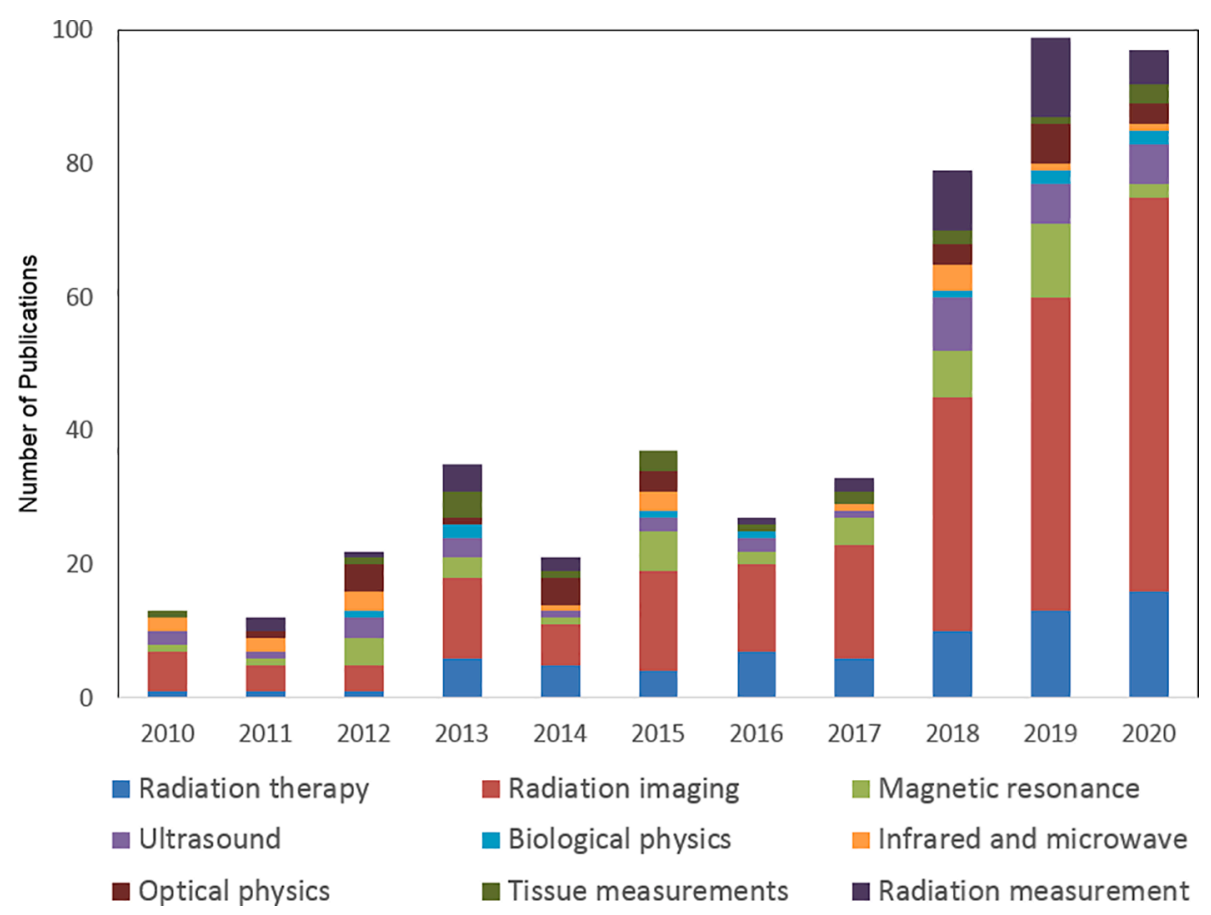

Fig. 5. The number of publications by authors from the mainland of China in the three top medical physics journals (Medical Physics, Physics in Medicine and Biology, and Physica Medica) between the years of 2010 and 2020.

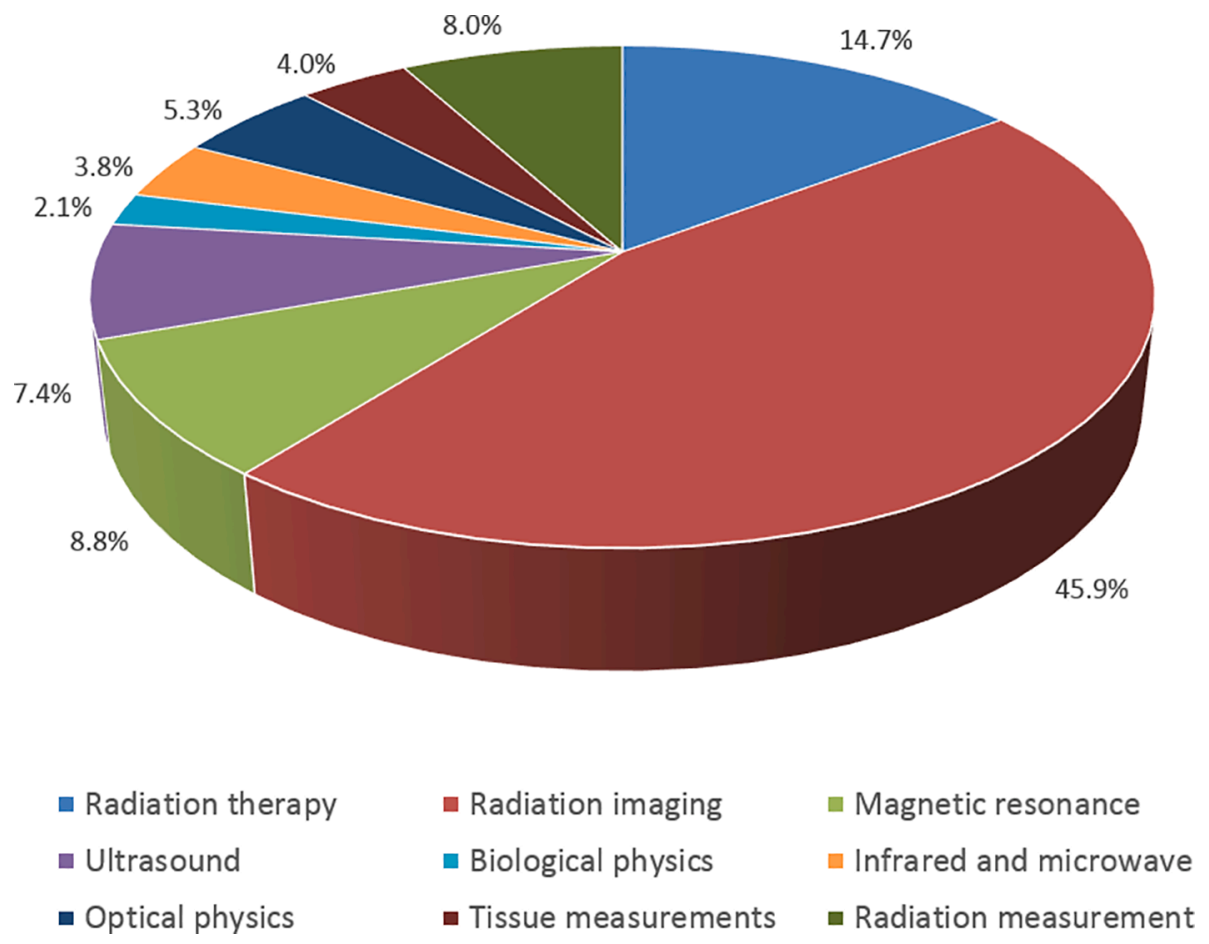

Fig. 6. The percentages of publications for 9 subspecialties of medical physics in the three top international medical physics journals (Medical Physics, Physics in Medicine and Biology, and Physica Medica) between 2010 and 2020.

oncology and 2000-3000 in radiology and nuclear medicine. The number of medical physicists in departments of radiation oncology has increased significantly in last decade. Now the ratio of the number of physicians to the number of physicists improved to $3.51: 1$ but there is still a certain distance to go to match those of developed countries. Given the fact that the workload of radiation oncology clinic is proportion to the number of patients under radiotherapy, this may further disadvantage medical physicists in regions with insufficient megavoltage treatment machines, such as Qinghai and Ningxia.

Also, for the two major municipalities (Beijing and Shanghai), medical physicists mostly work overtime due to the large number of patients under treatment. The reason is that cancer patients from adjacent provinces are keen to be treated at the top cancer hospitals located in these two Cities. The higher workload of medical physicists may raise 
radiation safety concerns, as the burnout phenomenon could negatively impact on their attention and performance. Medical physicists whose multiple appointments encompass more than one specialty raise additional concerns. In such cases, medical physicist competence over time is potentially challenged by the rapid and overwhelming development of all specialties in Medical Physics. In order to reduce the incidence of multi-shifting, the high demand placed on medical physicists in the major cancer hospitals needs to be alleviated.

There is a need for a higher degree as an entry requirement for the professional medical physicist to respond to the increasing complexity of modern medical physics. Most medical physics programs throughout the world are post-graduate programs that provide specialist knowledge on top of basic skills in physical sciences and mathematics. Clinical training should be required prior to being able to practice as medical physicist. For local hospitals, their medical physicists are usually trained in major cancer hospitals. However, so far there is no formal resident program for graduates of medical physics in China. High workload makes it difficult for major cancer hospitals to dedicate their experienced staffs to train young medical physicists from local hospitals.

To be able to work independently in the clinical centers, medical physicists need a high quality education and training program. Consistent requirements for medical physicists to work in clinical centers should be established and regulated by the government. A national certification board should be established based on active and experienced members of CSMP. Currently, there is no national evaluation system for trainee certification. The universities and major cancer hospitals should work together to build a high quality graduate program that can meet the certification requirements of the National Medical Physics Certification Board. As the Nation Cancer Center (NCC), CICAMS has made large effort to build a training program for young medical physics from nationwide hospitals. Since 2000, 20-40 young medical physicists are trained in CICAMS annually. Since 2015, an advanced medical physics training program is hosted by NCC and National Health Commission (NHC). Many instructors of this program are professors from top cancer hospitals in USA and Europe.

There is a rapid increase in publications in international medical physics journals in the recent years. This reflects the higher dedication and involvement of Chinese medical physicists in scientific research. However, it is noted that the percentage of radiation imaging in the publications is higher (46\%) than the other subspecialties. The percentage of radiation therapy (treatment planning, patient and machine specific quality assurance) is less (14.7\%) but higher than that of magnetic resonance imaging (8.8). With the introduction of new therapeutic and imaging devices, there should be more publications in developing novel treatment and verification approaches in radiotherapy. Also with the introduction of deep learning algorithms, the publications in autosegmentation and output prediction of treatment should increase rapidly. It is also found that more medical physicists in departments of radiation oncology are actively involved in the research of medical imaging which was formerly dominated by their colleagues in departments of radiology. The reason might be that more types of imaging are available in radiotherapy and the need for advanced imaging is promoted in clinics.

Medical physicists in China need better professional recognition. Efforts have been made in the past decades including the proposal in people's congress, publicity campaign, etc. However, the situation has not changed. Currently, there is no official career track specifically for the medical physicist. Most clinical medical physicists have their career title in three professional tracks: (1) clinical track for those working in medical imaging, radiation therapy, and radiation oncology; (2) engineering track for those working in device maintenance and repairing; (3) research track for those working in hospitals affiliated with universities and research institutes. Another issue is that the specialty of medical physics is not listed as an independent subject in the annual national examination held by NHC. Medical physicists need to take the examination in one of four relevant subjects (Radiology, nuclear medicine, ultrasound, radiotherapy) for the qualification for professional promotion. However, the courses of these four subjects are not specifically designed for the medical physicist and much of the content of the courses is irrelevant to the work of clinical medical physics. This makes the promotion of medical physicists in the departments of radiation oncology very difficult. As a result, many excellent medical physicists leave hospitals for companies which can provide them with a higher salary and better career titles. Many talented medical physics graduates are unwilling to stay in local hospitals and go to major hospitals or foreign hospitals. This situation should be improved with the proper adjustment of the current policy in the future.

\section{Conclusion}

There are many challenges in practicing medical physics in China, such as unbalanced geographical distribution, uneven manpower and benefit, lack of a high-quality education and training system, insufficient professional recognition, etc. However, we have witnessed the advanced treatment techniques, novel imaging and therapeutic devices, and the rapid growth of scientific research in recent years. With high demand of cancer treatment and strong support from the government, it is very promising for the large progress of medical physics in the future. This study provide a brief understanding of the current status of medical physics in radiotherapy in China and will guide the efforts in improving the quality of the current national healthcare system.

\section{Acknowledgement}

Author would like to thank friends and colleagues for their constructive comments and valuable suggestions. We also thank CSTRO and CSMP for their generosity in providing the important data. Finally, we express our gratitude to all colleagues who have contributed to the questionnaire in nationwide survey on the status of the departments of radiation oncology.

\section{References}

[1] International Atomic Energy Agency. Roles and Responsibilities, and Education and Training Requirements for Clinically Qualified Medical Physicists. IAEA Human Health Series No. 25. Vienna; 2013.

[2] American Association of Physicists in Medicine (AAPM) [Internet]. Licensure and the Medical Physicist's Role in the Practice of Medicine - A Guide for Administrators and Regulators. AAPM Policy Number PP 2-D; 2008 July 31.

[3] International Labour Office. ISCO-08 International Standard Classification of Occupations. Volume I: Structure, group definitions and correspondence tables. Geneve: ILO; 2012.

[4] International Organization for Medical Physics (IOMP) (2012) The medical physicist: role and responsibilities. IOMP policy statement no. 1.

[5] http://w1.siemens.com.cn/140years/index.aspx.

[6] Liu TF. History and heritage: development of radiation oncology in China. Int J Radiat Oncol Biol Phys 1996 Dec 1;36(5):1267-70.

[7] http://csmp.org.cn/news/abstract/index.htm.

[8] https://new.qq.com/omn/20200921/20200921A0EVXL00.html.

[9] https://www.sohu.com/a/353893775_100086120.

[10] http://bjyjs.yixie8.com.

[11] Yuan S, Lang L. Xu G The application of remote controlled cobalt-60 brachytherapy machine (Brachytron) in eighty-seven cervical cancer patients. Chinese Journal of Obstetrics and Gynecology 1979;14(1):14-8.

[12] Nuclear Energy Press 1999.

[13] Hu YM, Gu XZ, et al. The progress of conformal radiotherapy. Chinese Journal of Radiation Oncology 1997 March;6(1):8-11.

[14] Dai J, Hu Y, et al. Plan-specific dosimetric verification for patient treated with intensity-modulated radiation therapy. Chinese Journal of Radiation Oncology 2004;13(3):229-33.

[15] Round W, Jafari S, Kron T, Azhari H, Chhom S, Hu YM, et al. Brief histories of medical physics in Asia-Oceania. Australas Phys Eng Sci Med 2015 Sep;38(3): 381-98.

[16] http://csmp.org.cn.

[17] Hu YM. Medical physics in China the past, the present and the future. Physics 2007; 1:51-4.

[18] Yuan H, Li X, Jiang Q, Tan B. The medical physics development with Chinese characteristics is a landmark event - congratulations to China University will set up medical physics professional education, Chinese Journal of. Med Phys 2011 Nov;28)6:3070-3073. 
[19] Ka W. The status of medical physics education in China. Chinese Journal of Medical Physics 2002;19(4):198-9.

[20] Yuan M, Jiang Q, Li X, Tan B, Liu M, Mao K, Xu Z. the necessity to establish medical physicist education and training system to improve medical institute quality in China. Chinese Journal of Medical Physics,201229(3):3455-3462.

[21] Hu Z, Wang X, The China-France international radiation physics training program, Chinese Journal of Medical Physics 1987;3.

[22] Xia B, Liao F, Xu Z. The status and issues of medical physics. Medical Equipment 2011;24)2:60-61.

[23] Gu XZ, Feng NY, Yu Y. Investigation report on the composition, equipment and technical level of radiation therapy team in China. Radiation Oncology of China 1989;3(1):41-3.

[24] Zhang Y, Yi JL, Jiang W. Survey on the Basic Information of Personnel and Facilities of Radiotherapy in Chinese Mainland in 2019. China Cancer 2020;29 (5):321-6.

[25] Fu J, Ni C, Fu J. Research progress in dosimetry with MRI-Linac. Chinese Journal of Radiation Oncology 2020;29(5):396-400.

[26] Zheng RS, Sun KX, Zhang SW, Zeng HM, Zou XN, Chen R, et al. Report of cancer epidemiology in China, 2015. Zhonghua Zhong Liu Za Zhi. 2019 Jan 23;41(1): 19-28.

[27] Round WH, Jafari S, Kron T, et al. Brief histories of medical physics in AsiaOceania. Australas Phys Eng Sci Med 2015;38(3):381-98.

[28] Bellometti S, Nube G, Alongi F, Baiocchi C, Corti L, Di Biase S, et al. On the behalf of "Triveneto group of Italian Association of Radiotherapy and Clinical Oncology (AIRO)". Radiotherapy activities and technological equipment in Veneto, Italy: a report from the Rete Radioterapica Veneta. Radiol Med. 2021 Apr;126(4):623-9.

[29] INTERNATIONAL ATOMIC ENERGY AGENCY. Setting Up a Radiotherapy Programme, clinical, medical physics, raditation protetion and safety aspects. Vienna: IAEA; 2008.

[30] http://www.sdfmu.edu.cn/.

[31] http://www.usc.edu.cn/.

[32] http://www.mdjmu.cn/.

[33] https://mp.weixin.qq.com/s/esjLux83yG12i3_c2QWScQ.

[34] https://afomp.org/history/.

[35] https://afomp.org/science-committee/.

[36] https://www.journals.elsevier.com/medicine-in-novel-technology-and-devices/ editorial-board/professor-yubo-fan-phd.

[37] https://www.humanbrainmapping.org/i4a/pages/index.cfm?pageid=3910.

[38] https://afomp.org/education-and-training/.

[39] https://isisn.nsfc.gov.cn/egrantweb/.

[40] https://service.most.gov.cn/.

[41] He P, Li Q, Liu X, et al. Respiratory motion management using audio-visua biofeedback for respiratory-gated radiotherapy of synchrotron-based pulsed heavy-ion beam delivery. Med Phys 2014;41(11):111708.

[42] Li F, Ye P, Zhang H. Performance evaluation of a high-speed multileaf collimator in real-time IMRT delivery to moving targets. Med Phys 2016;43(3):1401-10.

[43] Luo H, Jin F, Yang D, et al. Interfractional variation in bladder volume and its impact on cervical cancer radiotherapy: Clinical significance of portable bladder scanner. Med Phys 2016;43(7):4412.

[44] Liao Y, Wang L, Xu X, et al. An anthropomorphic abdominal phantom for deformable image registration accuracy validation in adaptive radiation therapy. Med Phys 2017;44(6):2369-78.

[45] Dou H, Jiang S, Yang Z, Sun L, Ma X, Huo B. Design and validation of a CT-guided robotic system for lung cancer brachytherapy. Med Phys 2017;44(9):4828-37.

[46] Shao W, Tang X, Bai Y, et al. Modulation of lateral positions of Bragg peaks via magnetic fields inside cancer patients: Toward magnetic field modulated proton therapy. Med Phys 2017;44(10):5325-38.

[47] Xing Y, Wu X, Li Y, Zhao J. Homogeneity study of proton and carbon ion scanning beams using combinations of different spot sizes and grid sizes. Med Phys 2017; 44(11):6047-52.

[48] Zhou Z, Yang Z, Jiang S, Zhang F, Yan H. Design and validation of a surgical navigation system for brachytherapy based on mixed reality. Med Phys 2019;46 (8):3709-18.

[49] Fan Y, Yao X, Xu X. A robust automated surface-matching registration method for neuronavigation. Med Phys 2020;47(9):2755-67.

[50] Liang Z, Zhou Q, Yang J, Zhang L, Liu D, Tu B, et al. Artificial intelligence-based framework in evaluating intrafraction motion for liver cancer robotic stereotactic body radiation therapy with fiducial tracking. Med Phys 2020;47(11):5482-9.

[51] Ma P, Li Y, Tian Y, Liu B, Zhou F, Dai J. Design of a spherical applicator for intraoperative radiotherapy with a linear accelerator-a Monte Carlo simulation. Phys Med Biol 2018;64(1):015014.

[52] Wu J, Xie Y, Wang L, Wang Y. Monte Carlo simulations of energy deposition and DNA damage using TOPAS-nBio. Phys Med Biol 2020 Nov 12;65(22):225007.

[53] Zhao LR, Zhou YB, Li GH, et al. The clinical feasibility and performance of an orthogonal X-ray imaging system for image-guided radiotherapy in nasopharyngeal cancer patients: Comparison with cone-beam CT. Phys Med 2016;32(1):266-71.

[54] Li Y, Wang B, Ding S, Liu H, Liu B, Xia Y, et al. Feasibility of using a commercial collapsed cone dose engine for 1.5T MR-LINAC online independent dose verification. Phys Med 2020 Dec;80:288-96.

[55] Ma P, Li M, Chen X, Tian Y, Niu C, Feng Q, et al. Ultrasound-guided intraoperative electron beam radiation therapy: A phantom study. Phys Med 2020 Oct:78:1-7.

[56] Wu G, Shi Z, Chen Y, et al. A sparse representation-based radiomics for outcome prediction of higher grade gliomas. Med Phys 2019;46(1):250-61.
[57] Jiang D, Yan H, Chang N, Li T, Mao R, Du C, et al. Convolutional neural networkbased dosimetry evaluation of esophageal radiation treatment planning. Med Phys 2020;47(10):4735-42.

[58] Liu Z, Chen X, Men K, Yi J, Dai J. A deep learning model to predict dose-volume histograms of organs at risk in radiotherapy treatment plans. Med Phys 2020;47 (11):5467-81.

[59] Zhu J, Chen L, Jin G, Luo G, Cao W, Liu X. A comparison of VMAT dosimetric verifications between fixed and rotating gantry positions. Phys Med Biol 2013;58 (5):1315-22.

[60] Liu W, Ma X, Yan H, Chen Z, Nath R, Li H. Comparison of 2D and 3D modeled tumor motion estimation/prediction for dynamic tumor tracking during arc radiotherapy. Phys Med Biol 2017;62(9):N168-79.

[61] Li Y, Fan M, Cheng H, Zhang P, Zheng B, Li L. Assessment of global and local region-based bilateral mammographic feature asymmetry to predict short-term breast cancer risk. Phys Med Biol 2018;63(2):025004.

[62] Xia W, Chen Y, Zhang R, et al. Radiogenomics of hepatocellular carcinoma: multiregion analysis-based identification of prognostic imaging biomarkers by integrating gene data-a preliminary study. Phys Med Biol 2018;63(3):035044.

[63] Zhang J, Liu S, Yan H, Li T, Mao R, Liu J. Predicting voxel-level dose distributions for esophageal radiotherapy using densely connected network with dilated convolutions. Phys Med Biol 2020 Oct 21;65(20):205013.

[64] Jin X, Yi J, Zhou Y, Yan H, Han C, Xie C. A new plan quality index for nasopharyngeal cancer SIB IMRT. Phys Med 2014;30(1):122-7.

[65] Wang K, Meng H, Chen J, Zhang W, Feng Y. Plan quality and robustness in field junction region for craniospinal irradiation with VMAT. Phys Med 2018;48:21-6.

[66] Zhang K, Dai J, Hu Z, Niu C. Dosimetric impact of hysteresis on lung cancer tomotherapy: A moving phantom study. Phys Med 2018;49:40-6.

[67] Fan J, Wang J, Zhang Z, Hu W. Iterative dataset optimization in automated planning: Implementation for breast and rectal cancer radiotherapy. Med Phys 2017;44(6):2515-31.

[68] Fan J, Wang J, Chen Z, Hu C, Zhang Z, Hu W. Automatic treatment planning based on three-dimensional dose distribution predicted from deep learning technique. Med Phys 2019;46(1):370-81.

[69] Liu Z, Fan J, Li M, et al. A deep learning method for prediction of threedimensional dose distribution of helical tomotherapy. Med Phys 2019;46(5): 1972-83.

[70] Chen X, Men K, Li Y, Yi J, Dai J. A feasibility study on an automated method to generate patient-specific dose distributions for radiotherapy using deep learning. Med Phys 2019;46(1):56-64.

[71] Jin R, Min Z, Song E, Liu H, Ye Y. A novel fluence map optimization model incorporating leaf sequencing constraints. Phys Med Biol 2010;55(4):1243-64.

[72] Liang B, Li Y, Wei R, et al. A singular value decomposition linear programming (SVDLP) optimization technique for circular cone based robotic radiotherapy. Phys Med Biol 2018;63(1):015034.

[73] Zhuang Y, Han J, Chen L, Liu X. Dose-volume histogram prediction in volumetric modulated arc therapy for nasopharyngeal carcinomas based on uniformintensity radiation with equal angle intervals. Phys Med Biol. 2019;64(23): 23NT03.

[74] Jiao SX, Chen LX, Zhu JH, Wang ML, Liu XW. Prediction of dose-volume histograms in nasopharyngeal cancer IMRT using geometric and dosimetric information. Phys Med Biol. 2019;64(23):23NT04.

[75] Zhu J, Liu X, Chen L. A preliminary study of a photon dose calculation algorithm using a convolutional neural network. Phys Med Biol. 2020 Oct 16;65(20): $20 \mathrm{NTO2}$.

[76] Yang J, He P, Wang H, Sun G, Zheng H, Jia J. An improved beam splitting method for intensity modulated proton therapy. Phys Med Biol. 2020 Sep 18;65(18): 185015.

[77] Yan H, Dai JR. Intelligence-guided beam angle optimization in treatment planning of intensity-modulated radiation therapy. Phys Med 2016;32(10): 1292-301.

[78] Zhou Z, Zhang W, Guan S. An effective calculation method for an overlap volume histogram descriptor and its application in IMRT plan retrieval. Phys Med 2016; 32(10):1339-43.

[79] Men K, Chen X, Zhu J, Yang B, Zhang Y, Yi J, et al. Continual improvement of nasopharyngeal carcinoma segmentation with less labeling effort. Phys Med 2020 Dec;80:347-51.

[80] Fang S, Hu R, Yuan X, Liu S, Zhang Y. Resolution enhancement for lung 4D-CT based on transversal structures by using multiple Gaussian process regression learning. Phys Med 2020 Oct;78:187-94.

[81] Peng J, Zhang Z, Zhou L, et al. A study on investigating the delivery parameter error effect on the variation of patient quality assurance during RapidArc treatment. Med Phys 2013;40(3):031703.

[82] Wang Q, Dai J, Zhang K. A novel method for routine quality assurance of volumetric-modulated arc therapy. Med Phys 2013;40(10):101712.

[83] Xiao Q, Bai S, Li G, Yang K, Bai L, Li Z, et al. Statistical process control and process capability analysis for non-normal volumetric modulated arc therapy patientspecific quality assurance processes. Med Phys 2020;47(10):4694-702.

[84] Peng J, Zhang Z, Wang J, Xie J, Chen J, Hu W. Developing new extension of GafChromic RTQA2 film to patient quality assurance field using a plan-based calibration method. Phys Med Biol 2015;60(19):7533-42.

[85] Zhang B, Zhu J, Li Y, Chen S, Chen L, Liu X. Feasibility of lateral dose profile measurements in a small field using TLDs. Phys Med Biol. 2015;60(3):N47-N57.

[86] Zhuang Y, Li Y, Zhu J, Chen L, Liu X. A trial for EBT3 film without batch-specific calibration using a neural network. Phys Med Biol. 2019;64(5):05NT01. 
[87] Wang L, Li J, Zhang S, Zhang X, Zhang Q, Chan MF, Yang R, Sui J. Multi-task autoencoder based classification-regression model for patient-specific VMAT QA. Phys Med Biol. 2020 Nov 27;65(23):235023.

[88] Fan J, Xing L, Ma M, Hu W, Yang Y. Verification of the machine delivery parameters of a treatment plan via deep learning. Phys Med Biol. 2020 Sep 30;65 (19):195007.

[89] Hu Z, Li G, Zhang X, Ye K, Lu J, Peng H. A machine learning framework with anatomical prior for online dose verification using positron emitters and PET in proton therapy. Phys Med Biol. 2020 Sep 14;65(18):185003.

[90] Li G, Zhang Y, Jiang X, et al. Evaluation of the ArcCHECK QA system for IMRT and VMAT verification. Phys Med 2013;29(3):295-303.

[91] Jin GH, Zhu JH, Chen LX, et al. Gantry angle-dependent correction of dose detection error due to panel position displacement in IMRT dose verification using EPIDs. Phys Med 2014;30(2):209-14.

[92] Wang Y, Pang X, Feng L, Wang H, Bai Y. Correlation between gamma passing rate and complexity of IMRT plan due to MLC position errors. Phys Med 2018;47: $112-20$.

[93] Li J, Wang L, Zhang X, Liu L, Li J, Chan MF, Sui J, Yang R. Machine Learning for Patient-Specific Quality Assurance of VMAT: Prediction and Classification Accuracy. Int J Radiat Oncol Biol Phys. 2019 Nov 15;105(4):893-902.

[94] Liu Z, Liu X, Guan H, Zhen H, Sun Y, Chen Q, Chen Y, Wang S, Qiu J. Development and validation of a deep learning algorithm for auto-delineation of clinical target volume and organs at risk in cervical cancer radiotherapy. Radiother Oncol. 2020 Dec;153:172-179.

[95] Peng Y, Chen S, Qin A, Chen M, Gao X, Liu Y, Miao J, Gu H, Zhao C, Deng X, Qi Z. Magnetic resonance-based synthetic computed tomography images generated using generative adversarial networks for nasopharyngeal carcinoma radiotherapy treatment planning. Radiother Oncol. 2020 Sep;150:217-224.

[96] Song Y, Hu J, Liu Y, Hu H, Huang Y, Bai S, et al. Dose prediction using a deep neural network for accelerated planning of rectal cancer radiotherapy. Radiother Oncol 2020 Aug;149:111-6.

[97] Song Y, Hu J, Wu Q, Xu F, Nie S, Zhao Y, et al. Automatic delineation of the clinical target volume and organs at risk by deep learning for rectal cancer postoperative radiotherapy. Radiother Oncol 2020 Apr;145:186-92.

[98] Song Y, Wang Q, Jiang X, Liu S, Zhang Y, Bai S. Fully automatic volumetric modulated arc therapy plan generation for rectal cancer. Radiother Oncol 2016 Jun;119(3):531-6.

[99] Zhao Y, Qi G, Yin G, Wang X, Wang P, Li J, et al. A clinical study of lung cance dose calculation accuracy with Monte Carlo simulation. Radiat Oncol. 2014 Dec; 16(9):287.

[100] Shang DP, Liu CX, Yin Y. A comparison of the different 3D CT scanning modes on the GTV delineation for the solitary pulmonary lesion. Radiat Oncol. 2014 Nov;12 (9):211.

[101] Yu W, Shang H, Xie C, Han C, Yi J, Zhou Y, et al. Feasibility of constant dose rate VMAT in the treatment of nasopharyngeal cancer patients. Radiat Oncol. 2014 Nov;4(9):235.

[102] Xu H, Gong G, Wei H, Chen L, Chen J, Lu J, et al. Feasibility and potential benefits of defining the internal gross tumor volume of hepatocellular carcinoma using contrast-enhanced 4D CT images obtained by deformable registration. Radiat Oncol. 2014 Oct;16(9):221.

[103] Wang R, Zhang S, Yu H, Lin S, Zhang G, Tang R, et al. Optimal beam arrangement for pulmonary ventilation image-guided intensity-modulated radiotherapy for lung cancer. Radiat Oncol. 2014 Aug;16(9):184.

[104] Lin H, Huang S, Deng X, Zhu J, Chen L. Comparison of 3D anatomical dose verification and $2 \mathrm{D}$ phantom dose verification of IMRT/VMAT treatments for nasopharyngeal carcinoma. Radiat Oncol. 2014 Mar;7(9):71.

[105] Liu C, Gong G, Guo C, Liu T, Lu J, Zhao H, et al. The feasibility of evaluating radiation dose to the heart by integrating kilovoltage-cone beam computed tomography in stereotactic body radiotherapy of early non-small-cell lung cancer patients. Radiat Oncol. 2013 Dec;26(8):295.

[106] Jin X, Hu W, Shang H, Han C, Yi J, Zhou Y, et al. CBCT-based volumetric and dosimetric variation evaluation of volumetric modulated arc radiotherapy in the treatment of nasopharyngeal cancer patients. Radiat Oncol. 2013 Dec;1(8):279.

[107] Jin X, Han C, Zhou Y, Yi J, Yan H, Xie C. A modified VMAT adaptive radiotherapy for nasopharyngeal cancer patients based on CT-CT image fusion. Radiat Oncol. 2013 Nov;27(8):277.

[108] Wang JZ, Li JB, Wang W, Qi HP, Ma ZF, Zhang YJ, et al. Detection of interfraction displacement and volume variance during radiotherapy of primary thoracic esophageal cancer based on repeated four-dimensional CT scans. Radiat Oncol. 2013 Sep;27(8):224.

[109] Wang Z, Jiang W, Feng Y, Guo Y, Cong Z, Song B, et al. A simple approach of three-isocenter IMRT planning for craniospinal irradiation. Radiat Oncol. 2013 Sep; $17(8): 217$.

[110] Wang J, Hu W, Cai G, Peng J, Pan Z, Guo X, et al. Using corrected cone-beam CT image for accelerated partial breast irradiation treatment dose verification: the preliminary experience. Radiat Oncol. 2013 Sep;13(8):214.

[111] Wang W, Li JB, Hu HG, Li FX, Xu M, Sun T, et al. Correlation between target motion and the dosimetric variance of breast and organ at risk during whole breast radiotherapy using 4DCT. Radiat Oncol. 2013 May;2(8):111.

[112] Jin GH, Chen LX, Deng XW, Liu XW, Huang Y, Huang XB. A comparative dosimetric study for treating left-sided breast cancer for small breast size using five different radiotherapy techniques: conventional tangential field, filed-infiled, tangential-IMRT, multi-beam IMRT and VMAT. Radiat Oncol. 2013 Apr;15 (8):89.
[113] Hu W, Ye J, Wang J, Xu Q, Zhang Z. Incorporating breath holding and image guidance in the adjuvant gastric cancer radiotherapy: a dosimetric study. Radiat Oncol. 2012 Jun;20(7):98.

[114] Zheng X, Dai T, Shu X, Pu Y, Feng G, Li X, et al. A new method of lower extremity immobilization in radiotherapy. Radiat Oncol. 2012 Feb;29(7):27.

[115] Jiang X, Li T, Liu Y, Zhou L, Xu Y, Zhou X, et al. Planning analysis for locally advanced lung cancer: dosimetric and efficiency comparisons between intensitymodulated radiotherapy (IMRT), single-arc/partial-arc volumetric modulated arc therapy (SA/PA-VMAT). Radiat Oncol. 2011 Oct;21(6):140.

[116] Gong Y, Wang S, Zhou L, Liu Y, Xu Y, Lu Y, et al. Dosimetric comparison using different multileaf collimeters in intensity-modulated radiotherapy for upper thoracic esophageal cancer. Radiat Oncol. 2010 Jul;15(5):65.

[117] Hu W, Ye J, Wang J, Ma X, Zhang Z. Use of kilovoltage X-ray volume imaging in patient dose calculation for head-and-neck and partial brain radiation therapy. Radiat Oncol. 2010 Apr;19(5):29.

[118] Li Q, Gu W, Mu J, Yin W, Gao M, Mo J, et al. Collimator rotation in volumetric modulated arc therapy for craniospinal irradiation and the dose distribution in the beam junction region. Radiat Oncol. 2015 Nov;19(10):235.

[119] Zhao H, He M, Cheng G, Han D, Wu N, Shi D, et al. A comparative dosimetric study of left sided breast cancer after breast-conserving surgery treated with VMAT and IMRT. Radiat Oncol. 2015 Nov;17(10):231.

[120] Zhang T, Liang ZW, Han J, Bi JP, Yang ZY, Ma H. Double-arc volumetric modulated therapy improves dose distribution compared to static gantry IMRT and 3D conformal radiotherapy for adjuvant therapy of gastric cancer. Radiat Oncol. 2015 May;19(10):114.

[121] Yao L, Zhu L, Wang J, Liu L, Zhou S, Jiang S, et al. Positioning accuracy during VMAT of gynecologic malignancies and the resulting dosimetric impact by a 6 degree-of-freedom couch in combination with daily kilovoltage cone beam computed tomography. Radiat Oncol. 2015 Apr;26(10):104.

[122] Zhu J, Chen L, Chen A, Luo G, Deng X, Liu X. Fast 3D dosimetric verifications based on an electronic portal imaging device using a GPU calculation engine. Radiat Oncol. 2015 Apr;11(10):85.

[123] Guo B, Li J, Wang W, Xu M, Shao Q, Zhang Y, et al. Interobserver variability in the delineation of the tumour bed using seroma and surgical clips based on 4DCT scan for external-beam partial breast irradiation. Radiat Oncol. 2015 Mar;13(10):66.

[124] Huang B, Wu L, Lin P, Chen C. Dose calculation of Acuros XB and Anisotropic Analytical Algorithm in lung stereotactic body radiotherapy treatment with flattening filter free beams and the potential role of calculation grid size. Radiat Oncol. 2015 Feb;26(10):53.

[125] Feng Z, Wu H, Zhang Y, Zhang Y, Cheng J, Su X. Dosimetric comparison between jaw tracking and static jaw techniques in intensity-modulated radiotherapy. Radiat Oncol. 2015 Jan;27(10):28.

[126] Zhang G, Han D, Ma C, Lu J, Sun T, Liu T, et al. Gradient-based delineation of the primary GTV on FLT PET in squamous cell cancer of the thoracic esophagus and impact on radiotherapy planning. Radiat Oncol. 2015 Jan;9(10):11.

[127] Wang J, Hu W, Yang Z, Chen X, Wu Z, Yu X, et al. Is it possible for knowledgebased planning to improve intensity modulated radiation therapy plan quality for planners with different planning experiences in left-sided breast cancer patients? Radiat Oncol. 2017 May 22;12(1):85.

[128] Deng Z, Shen L, Zheng X, Zhou Y, Yi J, Han C, et al. Dosimetric advantage of volumetric modulated arc therapy in the treatment of intraocular cancer. Radiat Oncol. 2017 May 10;12(1):83.

[129] Liu X, Huang E, Wang Y, He Y, Luo H, Zhong M, et al. Dosimetric comparison of helical tomotherapy, VMAT, fixed-field IMRT and 3D-conformal radiotherapy for stage I-II nasal natural killer T-cell lymphoma. Radiat Oncol. 2017 Apr 27;12(1): 76.

[130] Feng Z, Tao C, Zhu J, Chen J, Yu G, Qin S, et al. An integrated strategy of biological and physical constraints in biological optimization for cervical carcinoma. Radiat Oncol. 2017 Apr 4;12(1):64.

[131] Liu F, Xi XP, Wang H, Han YQ, Xiao F, Hu Y, et al. PET/CT-guided dose-painting versus CT-based intensity modulated radiation therapy in locoregional advanced nasopharyngeal carcinoma. Radiat Oncol. 2017 Jan 13;12(1):15.

[132] Wu H, Jiang F, Yue H, Zhang H, Wang K, Zhang Y. Applying a RapidPlan model trained on a technique and orientation to another: a feasibility and dosimetric evaluation. Radiat Oncol. 2016 Aug 18;11(1):108.

[133] Feng Z, Yue H, Zhang Y, Wu H, Cheng J, Su X. Monte Carlo simulation of beam characteristics from small fields based on TrueBeam flattening-filter-free mode. Radiat Oncol. 2016 Feb;27(11):30.

[134] Mai Y, Kong F, Yang Y, Zhou L, Li Y, Song T. Voxel-based automatic multi-criteria optimization for intensity modulated radiation therapy. Radiat Oncol. 2018 Dec $5 ; 13(1): 241$

[135] Tong Y, Yin Y, Cheng P, Gong G. Impact of deformable image registration on dose accumulation applied electrocardiograph-gated 4DCT in the heart and left ventricular myocardium during esophageal cancer radiotherapy. Radiat Oncol. 2018 Aug 10;13(1):145.

[136] Chen L, Huang B, Huang X, Cao W, Sun W, Deng X. Clinical evaluation for the difference of absorbed doses calculated to medium and calculated to water by Monte Carlo method. Radiat Oncol. 2018 Jul 28;13(1):137.

[137] Zhao F, Shen J, Lu Z, Luo Y, Yao G, Bu L, et al. Abdominal DIBH reduces the cardiac dose even further: a prospective analysis. Radiat Oncol. 2018 Jun 22;13 (1):116.

[138] Yan H, Dai JR, Li YX. A fast optimization approach for treatment planning of volumetric modulated arc therapy. Radiat Oncol. 2018 May 30;13(1):101.

[139] Wang J, Chen Z, Li W, Qian W, Wang X, Hu W. A new strategy for volumetricmodulated arc therapy planning using AutoPlanning based multicriteria 
optimization for nasopharyngeal carcinoma. Radiat Oncol. 2018 May 16;13(1): 94.

[140] Zhu J, Bai T, Gu J, Sun Z, Wei Y, Li B, et al. Effects of megavoltage computed tomographic scan methodology on setup verification and adaptive dose calculation in helical TomoTherapy. Radiat Oncol. 2018 Apr 27;13(1):80.

[141] Yu G, Li Y, Feng Z, Tao C, Yu Z, Li B, et al. Knowledge-based IMRT planning for individual liver cancer patients using a novel specific model. Radiat Oncol. 2018 Mar 27;13(1):52.

[142] Sun WZ, Zhang DD, Peng YL, Chen L, Kang DH, Wang B, et al. Retrospective dosimetry study of intensity-modulated radiation therapy for nasopharyngeal carcinoma: measurement-guided dose reconstruction and analysis. Radiat Oncol, 2018 Mar 15;13(1):42.

[143] Cao Y, Zhu X, Ju X, Liu Y, Yu C, Sun Y, et al. Optimization of dose distributions of target volumes and organs at risk during stereotactic body radiation therapy for pancreatic cancer with dose-limiting auto-shells. Radiat Oncol. 2018 Jan 22;13 (1):11.

[144] Tong Y, Gong G, Su M, Yin Y. Comparison of the dose on specific 3DCT images and the accumulated dose for cardiac structures in esophageal tumors radiotherapy: whether specific 3DCT images can be used for dose assessment? Radiat Oncol. 2019 Dec 27;14(1):242.

[145] Ling C, Han X, Zhai P, Xu H, Chen J, Wang J, et al. A hybrid automated treatment planning solution for esophageal cancer. Radiat Oncol. 2019 Dec 19;14(1):232.

[146] Li WZ, Liang ZW, Cao Y, Cao TT, Quan H, Yang ZY, et al. Estimating intrafraction tumor motion during fiducial-based liver stereotactic radiotherapy via an iterative closest point (ICP) algorithm. Radiat Oncol. 2019 Oct 29;14(1):185.

[147] Xie K, Sun H, Gao L, Lin T, Sui J, Ni X. A comparative study of identical VMAT about two adjacent targets with and without fixed-jaw technique. Radiat Oncol. 2019 May 8;14(1):75.

[148] Pan Y, Yang R, Zhang S, Li J, Dai J, Wang J, et al. National survey of patient specific IMRT quality assurance in China. Radiat Oncol. 2019 Apr 25;14(1):69.

[149] Yu T, Li JB, Wang W, Xu M, Zhang YJ, Shao Q, et al. A comparative study based on deformable image registration of the target volumes for external-beam partial breast irradiation defined using preoperative prone magnetic resonance imaging and postoperative prone computed tomography imaging. Radiat Oncol. 2019 Mar $5 ; 14(1): 38$.
[150] Zhou S, Luo L, Li J, Lin M, Chen L, Shao J, et al. Analyses of the factors influencing the accuracy of three-dimensional ultrasound in comparison with cone-beam CT in image-guided radiotherapy for prostate cancer with or without pelvic lymph node irradiation. Radiat Oncol. 2019 Jan 29;14(1):22.

[151] Meng Y, Yang H, Wang W, Tang X, Jiang C, Shen Y, et al. Excluding PTV from lung volume may better predict radiation pneumonitis for intensity modulated radiation therapy in lung cancer patients. Radiat Oncol. 2019 Jan 14;14(1):7.

[152] Liu G, Hu F, Ding X, Li X, Shao Q, Wang Y, et al. Simulation of dosimetry impact of 4DCT uncertainty in 4D dose calculation for lung SBRT. Radiat Oncol. 2019 Jan 8;14(1):1

[153] Wang H, Liu J, Pi Y, Liu Q, Mi Y, Yang X, et al. Technical note: factors affecting dose distribution in the overlap region of two-segment total body irradiation by helical tomotherapy. Radiat Oncol. 2020 Nov 7;15(1):257.

[154] Chang Y, Xiao F, Quan H, Yang Z. Evaluation of OAR dose sparing and plan robustness of beam-specific PTV in lung cancer IMRT treatment. Radiat Oncol. 2020 Oct 17;15(1):241.

[155] Cao W, Zhuang Y, Chen L, Liu X. Application of dose-volume histogram prediction in biologically related models for nasopharyngeal carcinomas treatment planning. Radiat Oncol. 2020 Sep 15;15(1):216.

[156] Song Y, Zhang W, Zhang H, Wang Q, Xiao Q, Li Z, et al. Low-dose cone-beam CT (LD-CBCT) reconstruction for image-guided radiation therapy (IGRT) by threedimensional dual-dictionary learning. Radiat Oncol. 2020 Aug 12;15(1):192.

[157] Chen L, Bai S, Li G, Li Z, Xiao Q, Bai L, et al. Accuracy of real-time respiratory motion tracking and time delay of gating radiotherapy based on optical surface imaging technique. Radiat Oncol. 2020 Jul 10;15(1):170.

[158] Bai H, Zhu S, Wu X, Liu X, Chen F, Yan J. Study on the ability of 3D gamma analysis and bio-mathematical model in detecting dose changes caused by dosecalculation-grid-size (DCGS). Radiat Oncol. 2020 Jul 6;15(1):161.

[159] He X, Liu M, Zhang M, Sequeiros RB, Xu Y, Wang L, et al. A novel threedimensional template combined with MR-guided 125I brachytherapy for recurrent glioblastoma. Radiat Oncol. 2020 Jun 8;15(1):146.

[160] Shang H, Pu Y, Wang W, Dai Z, Jin F. Evaluation of plan quality and robustness of IMPT and helical IMRT for cervical cancer. Radiat Oncol. 2020 Feb 13;15(1):34. 